\title{
MICROWAVE HEATING OF CORDIERITE CERAMIC SUBSTRATE FOR AFTER TREATMENT SYSTEMS
}

\author{
R.C. Marin ${ }^{*}$, S. V. Savu² \\ ${ }^{1}$ University of Craiova, Doctoral School Acad. Radu Voinea, Romania \\ ${ }^{2}$ University of Craiova, Faculty of Mechanics \\ *Corresponding author’s e-mail address: marin.robert.i2q@student.ucv.ro
}

\begin{abstract}
Selective catalyst reduction is one of the most affordable and successful technologies aimed at reducing NOx emissions from diesel engines. However, the reduction process can be achieved if a certain temperature is reached for the ceramic substrate of the catalytic core. The required temperatures for catalytic reaction vary from $250^{\circ} \mathrm{C}$ to $450^{\circ} \mathrm{C}$ depending on the technology applied in the catalytic processes. This paper aims at presenting preliminary research in microwave cordierite heating, which is a type of magnesium aluminium silicate used as ceramic honeycomb substrate (catalyst monolith) in the after treatment system in the automotive industry. The research focused on testing the Mg2Al4Si5O18 composite material (cordierite) for different microwave heating regimes in order to establish the level of microwave power required for fast heating. This application will be subject for the further development of new MW-SCR after treatment systems in order to reduce the NOx emissions at cold start engine or low operating regimes of non-road mobile machinery engines. The ceramic composite material was heated for 5 levels of microwave power, from $600 \mathrm{~W}$ to $1400 \mathrm{~W}$, using a $6 \mathrm{~kW}$ microwave generator coupled with a matching load impedance tuner, and the temperatures were recorded using an IR pyrometer.
\end{abstract}

KEYWORDS: Microwave heating, Thermal runaway, Composite material.

\section{INTRODUCTION}

The new European directive related to limitations of NOx emissions from NRMM (Non-Road Mobile Machinery) included in the EU regulation 2016/1628 requires the implementation of green technologies in order to reduce the pollutant emissions from inland ships. The implementation of SCR technology in the shipping industry sector started with large cargo ships. Selective Catalytic Reduction (SCR) is a means of converting nitrous oxides in the exhaust, with the help of a catalyst, into diatomic nitrogen and water. A reductant Anhydrous Ammonia (NH3), Aqueous Ammonia (Ammonium Hydroxide) or Urea (Carbamide) solution is added to a stream of exhaust gas, and is adsorbed onto a catalyst. Carbon Dioxide $\left(\mathrm{CO}_{2}\right)$ is a reaction product when urea is used as the reductant [9]. It is called "selective" because it reduces the NOx level by using ammonia as a reductant in a catalyst system. The reducing agent reacts with NOx to convert pollutants into nitrogen, water and minimal amounts of carbon dioxide $\left(\mathrm{CO}_{2}\right)$. The reducing source is usually car quality urea, otherwise known as Diesel Exhaust Fluid, which can be rapidly hydrolysed to produce oxidizing ammonia in the exhaust stream. SCR technology alone can achieve NOx reductions by over $90 \%$. According to the research performed [1], the primary SCR reaction using V-SCR based on $\mathrm{V}_{2} \mathrm{O}_{5}-\mathrm{WO}_{3}-\mathrm{TiO}_{2}$ can be initiated for an effective temperature window between $300^{\circ} \mathrm{C}$ and $450^{\circ} \mathrm{C}$, but in some cases the temperature can be $550^{\circ} \mathrm{C}$ as well. Below $300^{\circ} \mathrm{C}$ the presence of moisture in the SCR device will affect the performance of the selective catalytic reduction device [2], [5]. During the normal engine operating mode ( $80-90 \%$ of rated power), the temperature can be reached by the SCR device, but at idle time, when the engines are running at less than $15 \%$ of the rated power, the catalyst reaction cannot be initiated. The steady state performance of internal combustion has improved noticeably over the years, both in terms of fuel consumption and emissions quality. This can be attributed to a range of developments including the use of common rail fuel injection, improved lubricants, more complex engine control strategies, and the use of catalytic converters on most vehicles. However, the cold-start performance of vehicle engines remains problematic. The NOx emissions are connected to fuel consumption. According to scientific literature [15], [16], over an urban drive 
cycle, the fuel consumption was shown to increase by $18 \%$ when the ambient temperature decreased from $31^{\circ} \mathrm{qwC}$ to $2^{\circ} \mathrm{C}$. In addition, similar research [17] pointed up data that showed that the fuel consumption of a gasoline engine decreased by an average of $10 \%$ over the duration of the NEDC when the start temperature increased from $25^{0} \mathrm{C}$ to $90^{\circ} \mathrm{C}$. Therefore, the presence of the SCR after treatment system is not enough to reduce the NOx emissions if the engine is cold. The paper aims to develop an auxiliary heating system in order to increase the temperature of the ceramic core of the selective catalytic systems. One of the most suitable and cheap ceramic substrates for SCR-based after treatment devices for combustion engines is cordierite.

The microwave sintering of materials has widely developed, taking into account the advantages of the process in terms of reducing sintering time and maintaining the small sizes of the grains [13]. Ceramics are the materials with best absorbance properties of microwaves and conversion of the high frequency electrical waves in to heat. The ceramics are used as support for the microwave heating of other materials [6]. The study reported how $\mathrm{Al}_{2} \mathrm{O}_{3}$ and other ceramic materials can be used as support for different classes of materials that could not be heated with microwaves due to their reflection coefficient. Regarding the microwave heating of ceramics [3], the researchers reported that one of the most unwanted phenomena is related to the thermal runaway of the materials during the heating process. The research has been oriented towards the optimization of the heating process in order to avoid the thermal runaway phenomena. Other researchers [4] investigated the interaction between the microwaves and the ceramic core of SCR. Their research focused on the experimental determination of the effective complex dielectric properties of zeolite coatings on cordierite substrates, and the approximation of the latter. The research has shown that the dielectric properties of the SCR core can improve the heating mechanism of the microwaves.

This paper aims to present preliminary research in the microwave heating of cordierite, which is a type of magnesium aluminium silicate used as a ceramic honeycomb substrate (catalytic monolith) in the after treatment system in the automotive industry. The research focused on testing the $\mathrm{Mg}_{2} \mathrm{Al}_{4} \mathrm{Si}_{5} \mathrm{O}_{18}$ composite material (cordierite) for different microwave heating regimes in order to establish the level of microwave power required for fast heating. Cordierite is a potential candidate for use in thermal insulators, among other applications, because of its low thermal expansion coefficient $(a=1-31068 \mathrm{C} 1)$ and thermal conductivity (1-2 W/mK) [10], [11], [12].

Microwave heating is a process which converts the high frequency electromagnetic waves into heat, having as principle of conversion the mechanical friction of the electric dipoles inside the material. The mechanical friction causes heat dissipation and therefore microwave heating is a volume heating. The paper aims to use a microwave generator as main thermal source for the cordierite ceramic core of SCR systems. The experimental program consisted in research oriented towards establishing to what extent the cordierite can be heated in the microwave field, focusing on reaching the temperatures required by catalytic reaction. The figure below shows the concept design of a coupling microwave generator for an existing commercial SCR after treatment device used in the automotive industry.

On the other hand, unwanted phenomena such as thermal runaway [14] and plasma microwave initiation have been studied in order to establish a heating mechanism aimed at avoiding the destruction of the samples.

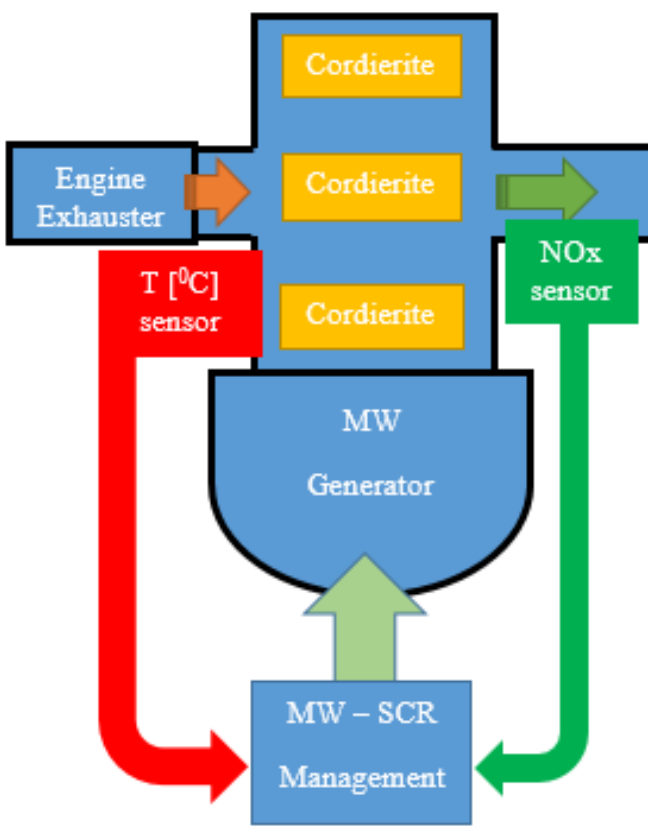

Fig. 1. Design concept of MW-SCR after treatment device

\section{MATERIALS AND METHODS}

The research was paper focused on cordierite ceramic, which is a composite material based on magnesium, aluminium, and silicate oxides. The presence of the oxygen in the structure of cordierite indicates that this material can be heated using high frequency electromagnetic waves. The chemical composition, according to scientific literature [7], is $\mathrm{Mg}-8.31 \%$, $\mathrm{Al}-18.45 \%, \mathrm{Si}-24.01 \%$ and $\mathrm{O}-49.23 \%$. In terms of oxides, the chemical composition is $\mathrm{MgO}_{2}$ $13.78 \%, \mathrm{Al}_{2} \mathrm{O}_{3}-34.86 \%$ and $\mathrm{SiO}_{2}-51.36 \%$. The raw mineral [8] is shown in the figure below.

The commercial honeycombs used in the experimental program have been extracted from a used SCR device. The figure below shows the cordierite composite material used in preliminary 
research related to microwave heating.

The original overall dimensions of the used ceramic honeycomb monolith were $200 \mathrm{~mm}$ in diameter and $600 \mathrm{~mm}$ length. Taking into consideration the dimensions of the heating chamber, the monolith has been cut in slices to reduce the dimensions of the samples. The shape of samples was kept cylindrical considering that the rounded shapes (spherical/cylindrical) are better at absorbing microwaves, and the conversion rate of the high frequency electromagnetic waves into heat is higher. Besides, the sharp samples or samples with rectangular shapes are lower absorbers of microwaves. The figure 2 shows the final shape and the sample dimension in the microwave field.

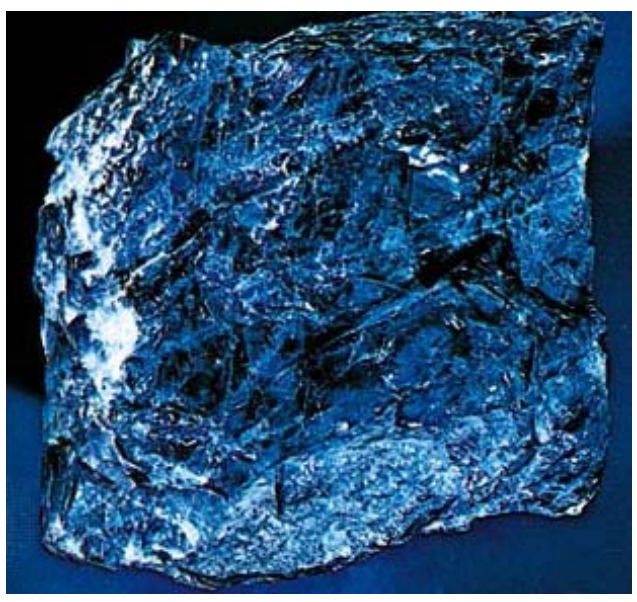

Fig. 2. Rock of cordierite

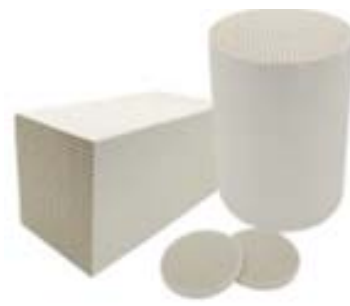

a.

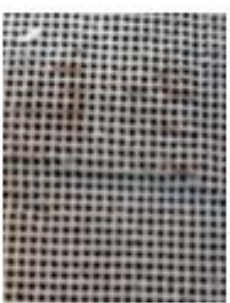

b.
Fig. 3. Ceramic honeycomb monolith a. new product (courtesy Baoan), b. used product

Microwave heating is usually unstable and irreproducible if a matching load impedance is not applied to the microwave generator. Previous research showed $[3,6]$ that the performance of the microwave heating is directly connected with the power absorbed by the sample. Therefore, a $6000 \mathrm{~W}$ Mugge watercooled microwave generator coupled with a Tristan matching load autotuner was used for the heating process. The temperature monitoring of the process was performed by means of an Optris CT LT infrared pyrometer having the measurement range between $-50^{\circ} \mathrm{C} \div 975^{\circ} \mathrm{C}$, driven by Compact Connect software provided by the manufacturer.
Previously, the emissivity of the cordierite was determined experimentally at 0.9214 for the temperature interval between $25^{\circ} \mathrm{C}$ and $600^{\circ} \mathrm{C}$. In addition, the heating process was driven by the dedicated Homer software installed in the process computer.

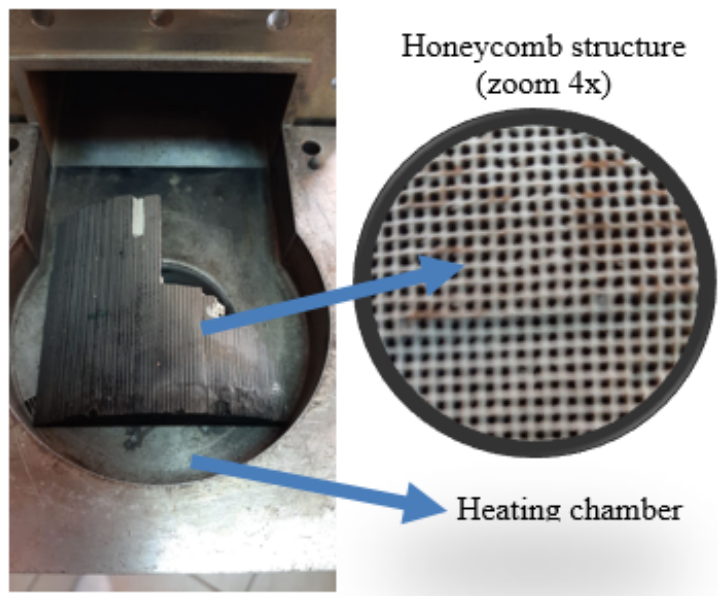

Fig. 4. Sample prepared for heating chamber

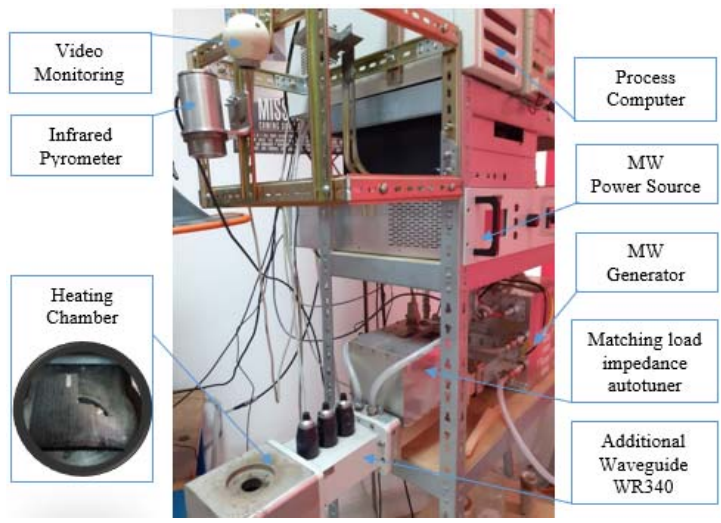

Fig. 5. Microwave heating device and auxiliary controls

One of the most important issues in SCR applications is related to the time required until the temperature of ceramic core reaches the ignition value for the catalytic reaction. The experimental program focused on obtaining the fast heating of cordierite in order to reach the temperature required by the SCR device. In addition, the occurrence of the thermal runaway phenomenon was observed in order to avoid the damage to the catalyst. The heating process started at $10 \%$ of the microwave generator power $(600 \mathrm{~W})$ and the input power increased by $200 \mathrm{~W}$ per experiment, up to $1400 \mathrm{~W}$. For ceramic materials, it was considered that this level of injected power was enough to fast heat the cordierite composite material. For each level of microwave power, the temperature evolution was recorded for the further optimization of the heating process. 


\section{RESULTS AND DISCUSSIONS}

The results obtained in all the five sessions of microwave heating were recorded by infrared pyrometer software for further analysis. The table below shows extras of the temperatures reached for each level of microwave power injected into the samples. Two aspects should be discussed in terms of the microwave heating of the cordierite material:

- the microwave heating mechanism;

- the thermal runaway phenomenon.

Table 1. Temperatures of cordierite in microwave

\begin{tabular}{|c|c|c|c|c|}
\hline $\begin{array}{c}\mathbf{P}_{\text {Mw }} \\
{[\mathbf{W}]}\end{array}$ & $\begin{array}{c}\text { TsCRmin } \\
{\left[{ }^{\mathbf{0}} \mathbf{C}\right]}\end{array}$ & $\begin{array}{c}\text { tsCRmin } \\
{[\mathbf{s}]}\end{array}$ & $\begin{array}{c}\mathbf{T}_{\text {SCRmax }} \\
{\left[{ }^{\mathbf{0}} \mathbf{C}\right]}\end{array}$ & $\begin{array}{c}\text { tsCRmax } \\
{[\mathbf{s}]}\end{array}$ \\
\hline 600 & 350.3 & 872 & 550.0 & 990 \\
800 & 348.9 & 843 & 553.2 & 891 \\
1000 & 351.2 & 311 & 539.7 & 375 \\
1200 & 348.5 & 260 & 549.9 & 322 \\
1400 & 349.9 & 223 & 535.2 & 267 \\
\hline
\end{tabular}

$\mathrm{P}_{\mathrm{MW}}$ is the total microwave power generated by the magnetron. $\mathrm{T}_{\mathrm{SCRmin}}$ is the minimum temperature for the SCR device in order to start the NOx reducing process. The $t_{S C R m i n}$ parameter is the total heating time until the cordierite temperature reaches the required temperature for the catalytic process. $\mathrm{T}_{\mathrm{SCRmax}}$ is the maximal temperature allowed for the ceramic core in order to avoid burning the SCR device, and $t_{\mathrm{SCR} \max }$ is the total heating time until the temperature reaches the maximal value allowed.

The experiments showed that the cordierite could be heated by means of microwave technology. The heating time, until reaching the ignition temperatures for the selective catalytic reaction $\left(\mathrm{T}_{\mathrm{SCR} \min }=350.3^{\circ} \mathrm{C}\right.$, $\left.\mathrm{t}_{\mathrm{SCRmin}}=872 \mathrm{~s}\right)$, is considerable, taking into consideration that the after treatment system should work when the combustion engine starts. By increasing the injected power from $600 \mathrm{~W}$ to $1400 \mathrm{~W}$, the heating time decreases, but the process becomes unstable. At the highest level of microwave-injected power $\left(\mathrm{P}_{\mathrm{MW}}=1800 \mathrm{~W}\right)$, the process is unstable, the thermal runaway occurs and the microwave plasma is initiated. However, in the case of injected power of $1200 \mathrm{~W}$, the heating time is slightly longer $\left(\mathrm{t}_{\mathrm{SCR}}=260\right.$ $\mathrm{s}$ ), but the process is stable during the catalytic process. In addition, the time interval between the lower temperature and the high temperature of the selective catalytic reduction process is the shortest from a thermal stability point of view. The figures below show the temperature evolution versus time for different levels of microwave power.

Figures $6 \mathrm{~b}$ and $6 \mathrm{e}$ show the point of thermal runaway phenomenon. For $\mathrm{P}_{\mathrm{MW}}=800 \mathrm{~W}$ the temperature increases smoothly until $351.3^{\circ} \mathrm{C}$ and then, due to short thermal runaway, the temperature increases fast up to $559^{\circ} \mathrm{C}$. The process is very fast and the gradient temperature is about $4.41 \%$ s. For $\mathrm{P}_{\mathrm{MW}}$ $=1400 \mathrm{~W}$ the temperature increases smoothly until $349.9^{\circ} \mathrm{C}$ and then, due to thermal runaway, the temperature increases fast up to $580^{\circ} \mathrm{C}$. The process is very fast and the gradient temperature is about $32.8 \%$. At this level of temperature increase the microwave plasma occurs and the process is interrupted by the microwave generator protection.

Figures $6 \mathrm{a}, 6 \mathrm{c}$ and $6 \mathrm{~d}$ show a smooth evolution of the temperatures, but in case of $\mathrm{P}_{\mathrm{MW}}=600 \mathrm{~W}$ the heating time is very long. On the other hand, in case of $\mathrm{P}_{\mathrm{MW}}=1000 \mathrm{~W}$ the heating time is shorter, but the curve shape is similar to the processes when thermal runaway occurred. However, in case of $\mathrm{P}_{\mathrm{MW}}=$ $1200 \mathrm{~W}$, the process is stable and the heating time is short. For this final case, a mathematical model has been elaborated for the microwave heating of cordierite. The equation below presents the linear approximation between the levels of microwave injected power and the heating time.

$$
T_{S C R}=a \cdot t_{S C R}+b
$$

where:

- parameter $T_{S C R}$ represents the temperature required by the after treatment system for reducing the NOx emissions;

- parameter $t_{S C R}$ represents the total heating time required by the after treatment system for reaching the catalytic temperature;

- parameters $a$ and $b$ are calculated and their values depend on the shapes, dimensions and position of the cordierite inside the heating chamber [18], [19];

For $\mathrm{P}_{\mathrm{MW}}=1200 \mathrm{~W}$, the parameters $a$ and $b$ were calculated using the linear approximation of the following values: $a=1.7377$ and $b=49.972$. The equation below represents a linear approximation of the heating process of the cordierite material.

$$
T_{S C R}=1.7377 \cdot t_{S C R}+49.972
$$

The shape and dimensions of the samples, as well as the position inside the heating chamber are relevant parameters for designing the microwave-activated SCR device. The actual SCRs have cylindrical shapes due to the vehicle design specs, but in case of the microwave-activated SCR, the uniform distribution of the temperature can also be obtained for the rectangular shape. This is very important when taking into account the rectangular shape of the waveguide.

Regarding the microwave plasma that could be initiated when heating the cordierite material, it was observed that this phenomenon occured when a high electrical polarization field was applied to the composite material.

The high polarization leads to a high density of electric carriers on the metallic surface of the heating chamber. Therefore, for the high power of the microwave field, tested at $30 \%$ of the microwave generator $\left(\mathrm{P}_{\mathrm{MW}}=1800 \mathrm{~W}\right)$ a microwave plasma is initiated. In terms of thermal runaway, as the 
triggering factor for microwave plasma, during microwave heating, this unwanted phenomenon can be avoided if the level of injected power is kept low. The thermal runaway phenomenon occurred after 110 $\mathrm{s}$ when the temperature could not be stabilized.

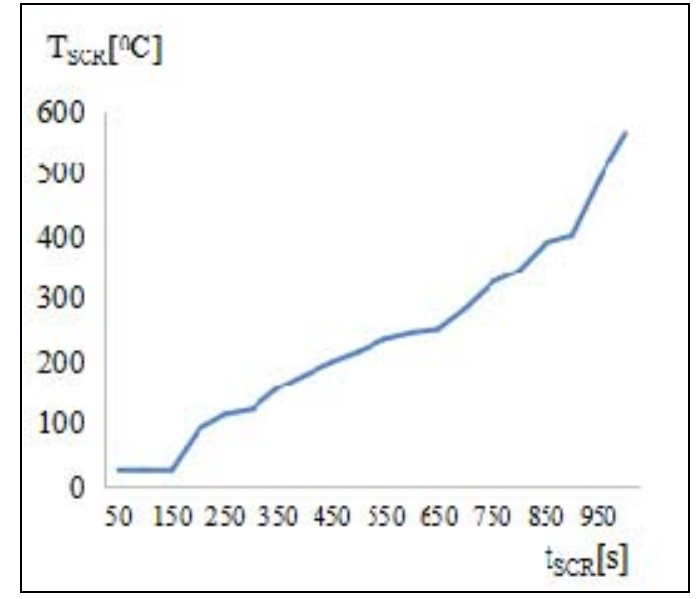

a.

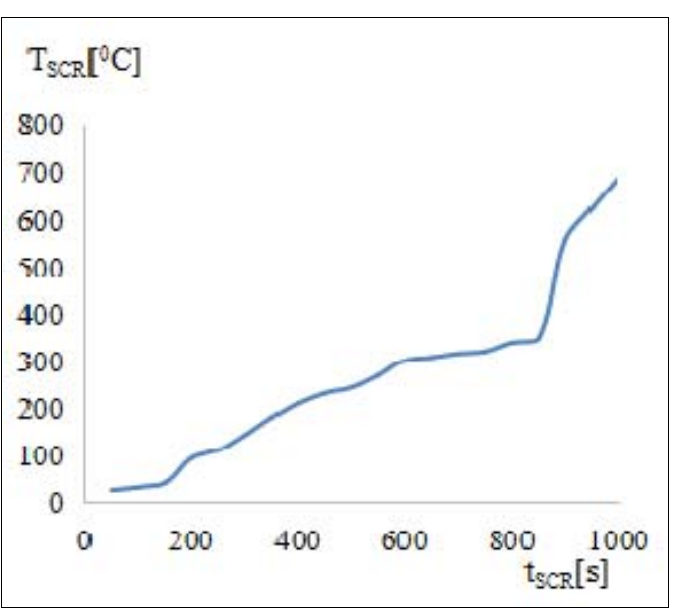

b.

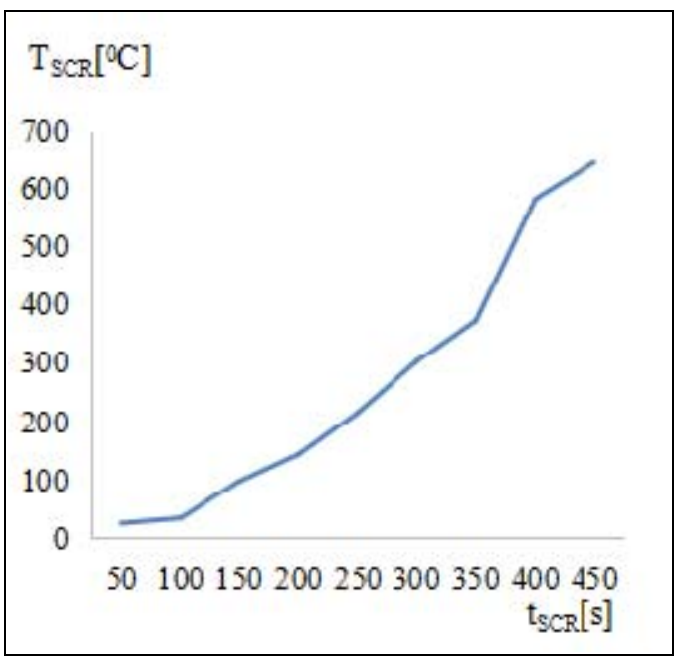

c.

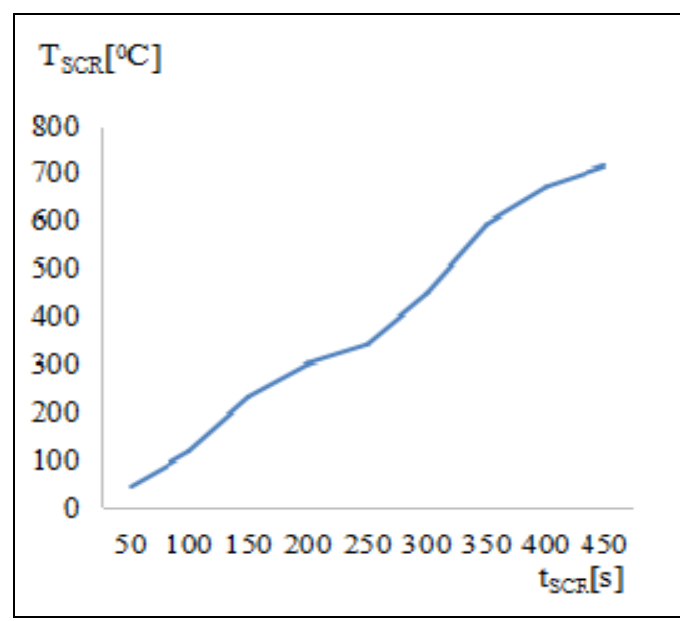

d.

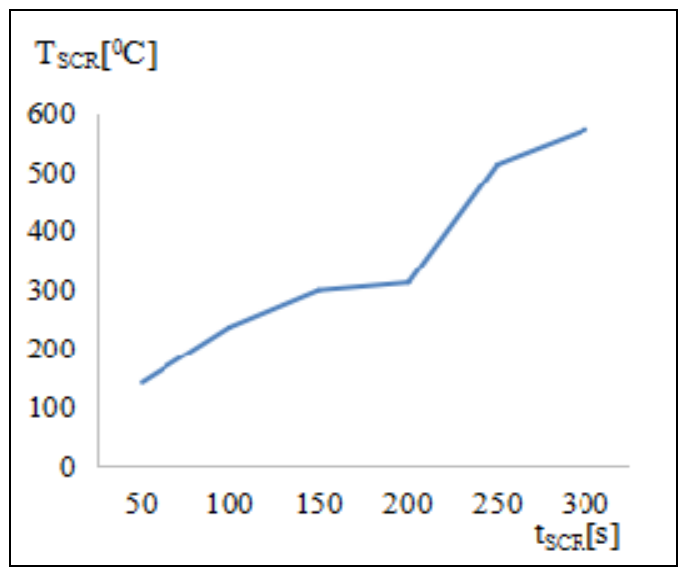

e.

Fig. 6. Temperature evolution of cordierite in microwave field: a. $600 \mathrm{~W}$, b. $800 \mathrm{~W}$, c. $1000 \mathrm{~W}$, d. $1200 \mathrm{~W}$, e. $1400 \mathrm{~W}$

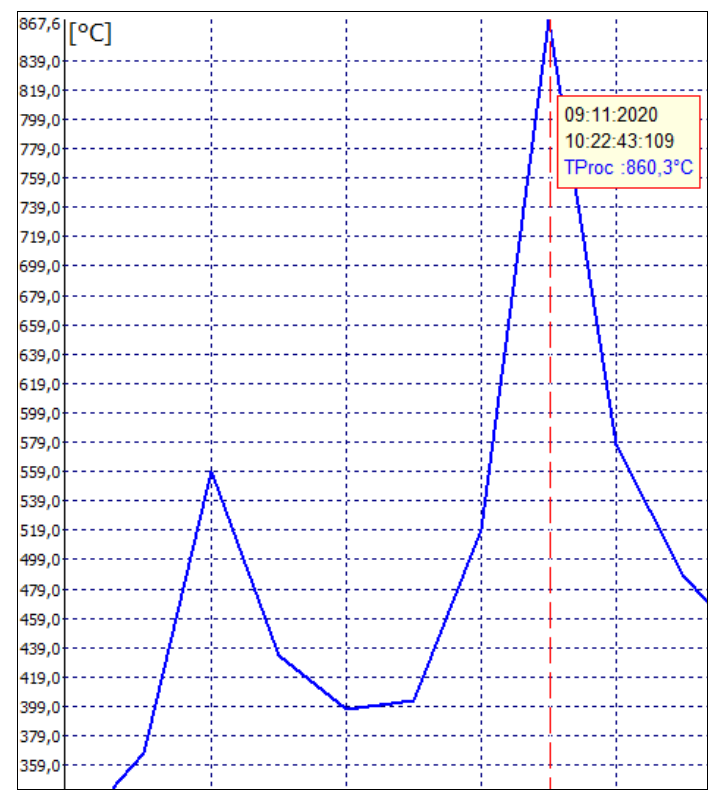

Fig. 7. Thermal runaway of cordierite in microwave 

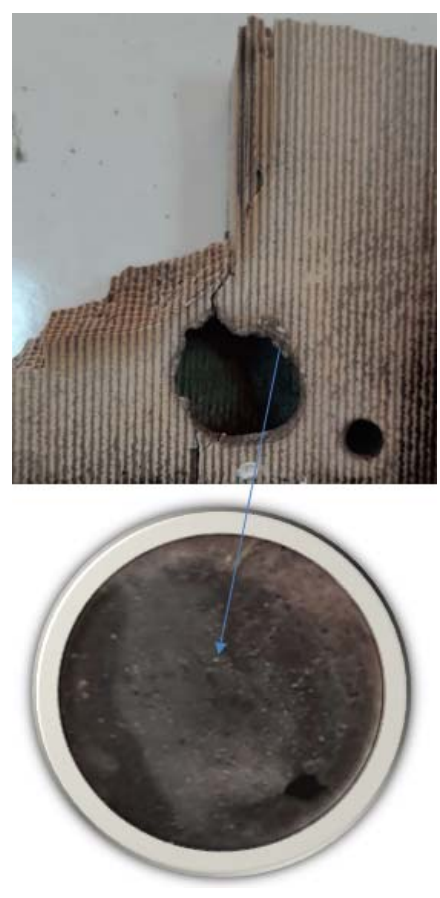

Fig. 8. Melted area and pitches on cordierite surface

The temperature increase was very fast, by about $50^{\circ} \mathrm{C} / \mathrm{s}$ from $564^{\circ} \mathrm{C}$ to $859^{\circ} \mathrm{C}$. Before thermal runaway, the microwave plasma arc was established and the temperature decreased from $551{ }^{\circ} \mathrm{C}$ to $397^{\circ} \mathrm{C}$. The heating process was stopped by the microwave source after the plasma arc discharge was detected.

After the cooling of the cordierite, an analysis was performed on the sample, revealing a melted point on the bottom of cordierite.

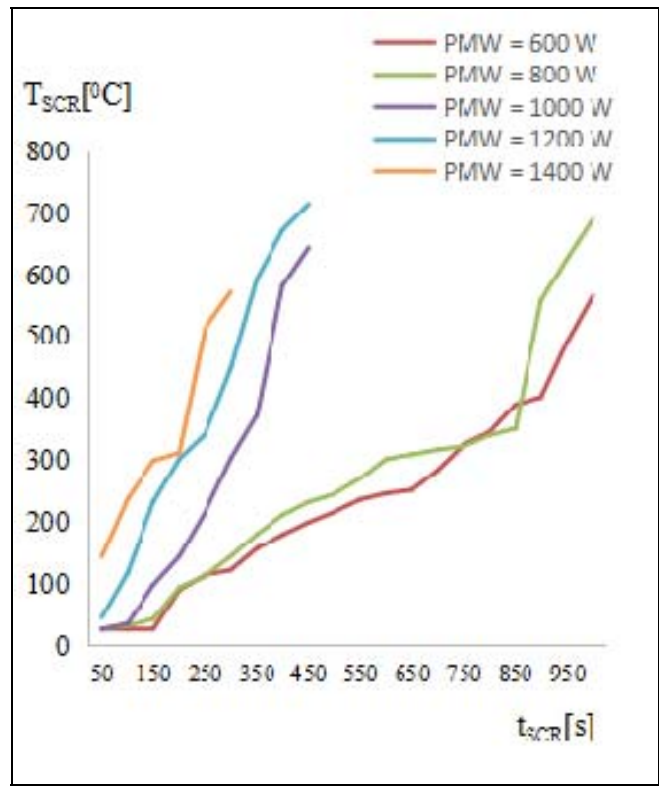

Fig. 9. Temperature evolution for different level of microwave power
The thermal runaway phenomenon occurred due to the discharge arc and the melting point reached on the bottom of the sample. The digital zoom of the piece broken from the original sample exhibited multiple pinches on the external side because the samples had been placed on the metallic surface.

The thermal runaway phenomenon is undesired for microwave application and its occurrence for cordierite starts when the level of microwave power injected into the samples is higher than $1200 \mathrm{~W}$. The figure below shows that for $1400 \mathrm{~W}$ the temperature increases very fast and the thermal runaway phenomenon occurs.

\section{CONCLUSIONS}

The aim of this paper was to establish if the cordierite can be heated in the microwave field in order to develop a hybrid SCR-MW device for NOx reduction. The MW-SCR device can be applied to older engines from inland ships, high agriculture machines and other non-road mobile machinery (NRMM) in order to meet the latest requirements in the EU Directive related to emission limitations.

The results obtained showed that the preheating time of the ceramic core of SCR is lower in case of microwave heating than other auxilliary thermal sources, like resistance heating [20]. Therefore, the energy consumption is lower in the case of microwave activation of SCR device, but the investment costs are higher. However, for NRMM the solution is suitable, taking into account the space, availability of power sources, as well as the costs for retrofitting that are lower than in case of modernisation of the NRMM with new engines.

The process of heating is stable for an input power of $1200 \mathrm{~W}$ where the ignition temperature of the SCR device occurs after $260 \mathrm{~s}$ (4.3 minutes), which can be optimized in terms of changing the shape of the samples. The process cannot be controlled without a matching load impedance tuner (manual or automatic) in order to create the specific conditions for optimal power transfer from the microwave generator towards the cordierite composite material.

The fast increase of temperature during the thermal runaway phenomenon leads to the ignition of the microwave plasma arc, and the samples were destroyed. The high polarization on the bottom of the heating chamber leads to arc discharge between cordierite and the metallic part of the heating chamber. The microwave plasma arc created a melting area on the bottom of the sample as well as electric pitches.

The microwave heating of cordierite must be optimized in order to reduce the injected power, maintaining a short heating time in order to avoid the unwanted phenomena like thermal runaway or microwave plasma. 


\section{REFERENCES}

[1] Zhan R., Possible Solutions for Reducing NOx and SOx Emissions from Large Cargo Ships, AIChE Spring Meeting and Global Congress on Process Safety, 2010.

[2] Culbertson D., Khair M., Zhang S., Tan J., Spooler J., The Study of Exhaust Heating to Improve SCR Cold Start Performance, SAE International Journal Of Engines, 2015, pp. 1187-1195.

[3] Savu I. D., Savu S. V., Benga G. C., Thermal Runaway of the $\mathrm{BaCO}_{3}+\mathrm{Fe}_{2} \mathrm{O}_{3}$ homogenous mixture and mechanical alloys at the microwave heating, Advanced Materials Research, 2014, pp. 185189.

[4] Dietrich M, Hagen G., Moos R., Dielectric properties and temperature dependency of automotive catalyst coatings and substrate materials: Experimental results, influences and approximation approach, Functional Materials Letters, 2019, pp. 1793-6047.

[5] Peng K., Zhou J., Xu W., You Z., Long W., Xiang M., Luo M., Microwave Irradiation-Selective Catalytic Reduction of NO to $\mathrm{N}_{2}$ by Activated Carbon at Low Temperature, Energy Fuels, 2017, pp. 7344-7351.

[6] Savu S. V., Procesarea materialelor în camp de microunde, Editura Universitaria, Craiova, 2013.

[7] Webmineral, General Cordierite Information, http://webmineral.com/data/Cordierite.shtml\#.X6kbR1pxeUk

[8] Augustyn A. et al., Cordierite, Encyclopædia Britannica, 2019.

[9] Mathur A., Selective Catalytic Reduction (SCR) Reactor for Ships - Types, Working Principle, advantages and disadvantages, Marine technology, 2020.

[10] M. L. Sandoval et. al., Microwave sintering of cordierite precursor green bodiesprepared by starch consolidation, Ceramics International, 2011, pp. 1237 - 1243.
[11] Subramaniam M.A., Corbin D. R., Chowdhry U., Better ceramic substratesthrough zeolites, Bull. Mater. Sci. , 1993, pp. 665-678.

[12] Yamuna A., Honda S., Sumita K., Yanagihara M. Hashimoto S., Awaji H., Synthesis, sintering and thermal shock resistance estimation of porouscordierite by IR heating technique, Micropor. Mesopor. Mater. 85, 2005, pp. 169-175.

[13] Ju Shaohua et. al., Recent developments in the application of microwave energy in process metallurgy at KUST, Mineral Processing and Extractive Metallurgy Review, 2018, pp. 181-190

[14] Hayashi M. et al., Carbothermic Reduction of Hematite Powders by Microwave Heating, ISIJ International, 2013, pp. 1125-1130.

[15] Andrews G., Ounzain A., Li H., Bell M., Tate J., Ropkins $\mathbf{K}$., The use of a water/lubeoil heat exchanger and enhanced cooling water heating to increase water andlube oil heating rates in passenger cars for reduced fuel consumption and CO2emissions during cold start, SAE technical paper, 2007.

[16] Roberts A., Brooks R., Shipway P., Internal combustion engine cold-start efficiency: A review of the problem, causes and potential solutions, Energy Conversion and Management, 2014, $327-350$.

[17] Kunze K., Wolff S., Lade I., Tonhauser J., A systematic analysis of CO2-reductionby an optimized heat supply during vehicle warm-up, SAE technical paper, 2006.

[18] Zhijun Z., Tianyi S., Shiwei Z., Shape Effect on the Temperature Field during Microwave Heating Process, Journal of Food Quality, 2018, pp. 1-24.

[19] Curet S., Rouaud O., Boillereaux L., Effect of sample size on microwave power absorption within dielectric materials: $2 D$ numerical results vs. closed-form expressions, American Institute of Chemical Engineers AIChE J, 2009.

[20] Harder H. D., Brugger M., Brück R., Future SCR NOX Aftertreatment Systems for Euro 6, 2013. 